\title{
Non-communicable diseases in the Western Area District, Sierra Leone, before and during the Ebola outbreak
}

\author{
T. Samba, ${ }^{1}$ P. Bhat, ${ }^{2}$ P. Owiti, ${ }^{3,4}$ L. Samuels, ${ }^{1}$ P. J. Kanneh, ${ }^{1}$ R. Paul, ${ }^{1}$ B. Kargbo, ${ }^{5}$ A. D. Harries ${ }^{4,6}$
}

http://dx.doi.org/10.5588/pha.16.0086

Setting: Twenty-seven peripheral health units, five secondary hospitals and one tertiary hospital, Western Area District, Sierra Leone.

Objectives: To describe reporting systems, monthly attendances and facility-based patterns of six non-communicable diseases (NCDs) in the pre-Ebola and Ebola virus disease outbreak periods.

Design: A cross-sectional study using programme data. Results: Reporting was $89 \%$ complete on the six selected NCDs pre-Ebola and $86 \%$ during the Ebola outbreak $(P<0.01)$. Overall, marked declining trends in NCDs were reported during the Ebola period, with a monthly mean of 342 cases pre-Ebola and 164 during the Ebola outbreak. The monthly mean number of cases per disease in the pre-Ebola and Ebola outbreak periods was respectively 228 vs. 85 for hypertension, 43 vs. 27 for cardiovascular diseases, 36 vs. 18 for diabetes and 25 vs. 29 for peptic ulcer disease; this last condition increased during the outbreak. There were higher proportions of NCDs among females during the Ebola outbreak compared with the pre-Ebola period. Except for peptic ulcer disease, the number of patients with NCDs declined by $25 \%$ in peripheral health units, $91 \%$ in the secondary hospitals and $70 \%$ in the tertiary hospital between the pre-Ebola and the Ebola outbreak periods.

Conclusion: Comprehensive reporting of NCDs was suboptimal, and declined during the Ebola epidemic. There were decreases in reported attendances for NCDs between the pre-Ebola and the Ebola outbreak periods, which were even more marked in the hospitals. This study has important policy implications.

$\mathbf{N}$ on-communicable diseases (NCDs) are now the world's leading cause of morbidity and mortality, with particularly devastating human, social and economic consequences in poor and vulnerable populations. ${ }^{1-3}$ Cancer, ischaemic heart disease, stroke and diabetes are the predominant causes of death globally, including in low- and middle-income countries (LMICs). ${ }^{3}$ To deal with this growing problem, in 2011 the United Nations developed targets to reduce premature mortality due to NCDs, 4,5 and these have been brought forward into the Sustainable Development Goals (SDG), with SDG 3.4 aiming to reduce premature mortality from NCDs by one third by the year $2030 .{ }^{6}$ While there is increasing agreement about the upstream policies needed to combat NCDs and reduce NCD mortality, far less is known downstream about how to deliver and monitor quality services for the prevention, care and treatment of NCDs for the millions of people in need.

In LMICs, patients with NCDs are usually managed in tertiary or secondary level hospitals, although there is growing experience with the management and care of NCDs in the primary health care setting. ${ }^{7,8}$ In Sierra Leone, NCDs are also generally managed at tertiary and secondary level hospitals. Peripheral health units (PHUs), however, have increasingly begun to take on this workload with established referral mechanisms to ensure that patients with selected NCDs (e.g., diabetes, epilepsy) or severe complications from hypertension or peptic ulcer disease can be referred from primary health care level to secondary or tertiary care facilities.

In 2014, Sierra Leone was hit by the Ebola virus disease (EVD) epidemic, which started in neighbouring Guinea in December 2013. ${ }^{9}$ By 3 January 2016, a cumulative total of 14122 cases had been reported in the country, of whom 3955 died. ${ }^{10}$ Both the health system and the delivery of health services were badly affected during the epidemic, with decreasing vaccination coverage and disruption of programmes for tuberculosis, acquired immune-deficiency disease and malaria due to the closure of clinics and the repurposing of clinical teams and facilities to the Ebola response. ${ }^{11}$ For a country already severely lacking in skilled health-care staff, this shortage was exacerbated by the tragic deaths of several hundred health-care workers.

Despite some available information on the effect of Ebola on communicable diseases, ${ }^{11}$ there is no published or reported information in Sierra Leone or the affected neighbouring countries about the effect of the Ebola outbreak on NCDs. With clinic closures, extreme shortages of health-care workers and the repurposing of staff to the Ebola response, it could be expected that the numbers of persons diagnosed, managed and reported with NCDs at all levels of the health-care system might have been compromised. The specific objectives of this study were therefore to determine whether, for patients with selected NCDs at different health facilities in the Western Area District of Sierra Leone, the reporting systems, monthly attendances and health facility-based disease patterns differed between the pre-Ebola and the Ebola outbreak periods.

\section{METHODS}

Study design

This was a cross-sectional study using routine records.
AFFILIATIONS

1 Western Area District Health Management Team, Ministry of Health and Sanitation (MoHS), Freetown, Sierra Leone

2 Ministry of Health,

Government of Karnataka, Bengaluru, India

3 Academic Model Providing Access to Health Care (AMPATH), Eldoret, Kenya

4 International Union Against Tuberculosis and Lung Disease, Paris, France 5 MoHS, Freetown, Sierra Leone

6 London School of Hygiene \& Tropical Medicine, London, UK

\section{CORRESPONDENCE}

Thomas Samba

District Health Management

Team, Western Area

Ministry of Health and Sanitation

PMO Compound

Queen Elizabeth 11 Road

Cline Town

Freetown

Sierra Leone

e-mail: ttsamba@yahoo.com

KEY WORDS

SORT IT; operational research; cardiovascular disease; hypertension; diabetes mellitus
Received 29 September 2016 Accepted 26 November 2016

PHA2017;7(S1):S16-S21 (C) 2017 The Union 
Setting

General setting

Sierra Leone, located on the west coast of Africa, shares borders with Guinea and Liberia. The country has a land area of $71740 \mathrm{~km}^{2}$ and a population of approximately 7 million, based on the 2015 national census. ${ }^{12}$ Gross national income per capita is USD $1340 .{ }^{13}$ The network of public health facilities delivering services throughout the country provides care on a pay-per-service basis, with the exception of children aged $<5$ years, pregnant women, lactating mothers and Ebola survivors, who are covered by the free health care policy. Public health care services are further supplemented by services in the private sector, industry and non-governmental organisations, including faith-based facilities.

Study site

The Western Area District, situated in the western part of the country, is home to the capital city, Freetown. The district has a population of approximately 1.5 million, of whom $80 \%$ live in urban areas. The district has 110 functional PHUs, stratified into three categories, in order of hierarchy, from maternal and child health posts, to community health posts to community health centres, and these are managed by different cadres of health staff. There are 9 secondary level hospitals ( 5 of which are in the public sector and managed by medical officers) and 4 tertiary level hospitals ( 1 for paediatrics, 1 for obstetrics and gynaecology, 1 for mental health and 1 for internal medicine and surgery). The district health management team (DHMT), headed by the district medical officer, coordinates all health activities in the district, and all PHUs report directly to the DHMT. Secondary and tertiary hospitals have their own management committees and health boards, which are semi-autonomous and report directly to the Directorate of Health Systems, Policy, Planning and Information (DHSPPI) at the Ministry of Health and Sanitation (MoHS).

One tertiary care hospital (for internal medicine) and five secondary hospitals in the public sector were selected for this study. A convenience sample of 27 PHUs was selected as being representative of the 110 PHUs in the district, based on geographical location, hierarchical category and size.

Management of Ebola in the Western Area District The Ebola outbreak response consisted of teams organised for surveillance, social mobilisation, nutrition, logistics, laboratory support, case management and burials, with a central command centre to provide coordination. Protocols and policies were developed to guide response-related operations, and staff were trained and deployed as appropriate. Social mobilisation teams were regularly visible in the community using various media to disseminate health messages to individuals and households. People with suspected Ebola were placed in isolation units and tested for EVD. Patients who tested positive for EVD were transferred to Ebola treatment units, while negative cases were sent to routine clinics. The contacts of positive cases were followed up for 21 days. Those patients who died were buried in a safe and dignified manner by burial teams.
Detection, diagnosis, management and monitoring of NCDs

A directorate of NCDs, research and post-graduate training was created in 2008 within the MoHS. Guidelines from the directorate recommend which NCDs can be treated at the peripheral level, how these conditions and diseases should be managed and the criteria for referral. A range of NCDs can be diagnosed the PHU level, including hypertension (HTN), cardiovascular disease (CVD), diabetes mellitus (DM), peptic ulcer disease (PUD), cancer/tumour and mental health disease (MHD). HTN and PUD can be treated at the PHU level, while the other conditions need referral, treatment prescription and follow-up at secondary or tertiary level. Patients can also directly access secondary and tertiary level care to be diagnosed and treated for their NCDs. At the different levels of the health care system, health workers are trained to detect, diagnose, manage and refer patients with NCDs. There is a range of essential drugs for each condition, varying from simple or first-line drugs, available at the PHU and secondary hospital level, to more advanced therapies at the tertiary level.

At the PHU level, monthly reports on the numbers of patients with selected NCDs, stratified by sex and age group ( $0-14$ and $\geqslant 15$ years), are sent to the DHMT, where they are collated into monthly summaries for the out-patient morbidity forms by the monitoring and evaluation (M\&E) officers and sent to the DHSPPI, where data can be obtained by the directorate for NCDs. Monthly reports are also compiled at the secondary and tertiary levels by the M\&E officers and sent directly to the DHSPPI.

\section{Study population}

The present study included all patients reported with the selected NCDs (HTN, CVD, DM, PUD, cancer/tumour and MHD) who attended the 27 PHUs, 5 secondary hospitals and 1 tertiary hospital (for internal medicine) in Western Area District during the pre-Ebola (June 2013-April 2014) and Ebola outbreak (June 2014-April 2015) periods.

Data variables, sources of data and data collection Data variables included year, month, sex, monthly reports submitted and completed with all information recorded for the NCDs, and the monthly number of cases with PUD, CVD, HTN, MHD, DM and cancer/tumour. The sources of data were the collated monthly out-patient morbidity forms from the PHUs and the collated monthly forms from the secondary and tertiary hospitals in the DHSPPI.

\section{Analysis and statistics}

The data were collected and analysed in EpiData (v. 3.1 for entry and v. 2.2.2.182 for analyses, EpiData Association, Odense, Denmark). A descriptive analysis was performed. The proportions of patients with the selected NCDs were also analysed and compared between the pre-Ebola and the Ebola periods for each level of care using the $\chi^{2}$ test, odds ratios (OR, where appropriate, with 95\% confidence intervals (CI) and levels of significance set at 5\% $(P<0.05)$.
ACKNOWLEDGEMENTS

This research was conducted through the Structured

Operational Research and

Training Initiative (SORT IT) a global partnership led by the Special Programme for Research and Training in Tropical Diseases at the World Health Organization (WHO/TDR, Geneva, Switzerland). The training model is based on a course developed jointly by the International Union Against Tuberculosis and Lung Disease (The Union, Paris, France) and Médecins Sans Frontières (MSF, Geneva, Switzerland). The specific SORT IT programme that resulted in this publication was jointly developed and implemented by the $\mathrm{WHO}$ / TDR, the Sierra Leone Ministry of Health and Sanitation (Freetown), the WHO Sierra Leone Country Office (Freetown) and the Centre for Operational Research, The Union. Mentorship and the coordination/facilitation of the SORT IT workshops were provided through the Centre for Operational Research, The Union; The Union SouthEast Asia Office (New Delhi, India); Ministry of Health, Government of Karnataka, Karnataka, India; the Operational Research Unit (LUXOR), MSF, Brussels Operational Centre, Luxembourg; Academic Model Providing Access to Health Care (AMPATH, Eldoret, Kenya); Alliance for Public Health (Kiev, Ukraine); Institute of Tropical Medicine (Antwerp, Belgium);

University of Toronto

(Toronto, ON, Canada);

Dignitas International

(Zomba, Malawi); Partners in Health, Sierra Leone (Boston, MA, USA); and Baroda Medical College (Gujarat, India).

The programme was funded by the Department for International Development (London, UK) and the WHO/ TDR. The funders had no role in the study design, data collection and analysis, decision to publish or preparation of the manuscript.

Conflicts of interest: none declared.

In accordance with the WHO's open-access publication policy for all work funded by the WHO or authored/co-authored by WHO staff members, the WHO retains the copyright of this publication through a Creative Commons Attribution IGO licence (http://creativecommons. org/licenses/by/3.0/igo/ legalcode) that permits unrestricted use, distribution and reproduction in any medium provided the original work is properly cited. 


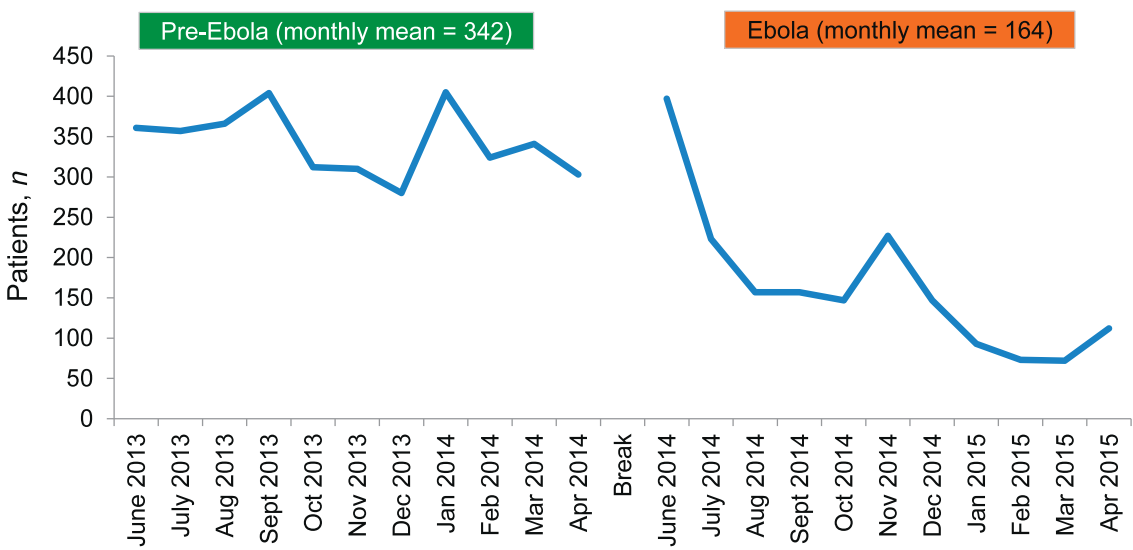

FIGURE 1 Numbers of patients reported each month with all types of NCDs at health facilities in the pre-Ebola and Ebola disease outbreak periods, Western District, Sierra Leone, 2013-2015. Pre-Ebola period = 1 June 2013-30 April 2014. Ebola period = 1 June 2014-30 April 2015. NCD = non-communicable diseases.

\section{Ethics approval}

Approval for the study was obtained from the Ethics and Scientific Review Committee (Freetown) and the Sierra Leone MoHS (Freetown). Ethics approval was also obtained from the Ethics Advisory Group of the International Union Against Tuberculosis and Lung Disease (Paris, France). As aggregate data were used with no identifiers, informed patient consent was not required.

\section{RESULTS}

\section{Monthly reporting and completeness of data}

Of the 33 facilities, 726 monthly reports (363 each from the pre-Ebola and the Ebola periods) were available for review covering 22 months of the study period. Of these, complete availability of information on the six selected NCDs was $89 \%$ in the pre-Ebola period and $86 \%$ in the Ebola period $(P<0.01)$.

\section{Trends of non-communicable diseases}

For the six selected NCDs combined, the numbers of patients reported each month during the pre-Ebola and the Ebola outbreak periods are shown in Figure 1. There was a declining trend in the pre-Ebola period that became more marked in the Ebola period, and the mean monthly numbers decreased from the pre-Ebola period to the Ebola period. For each selected NCD, the numbers reported each month during the pre-Ebola and the Ebola outbreak periods are shown in Figure 2A-2F. While five of the selected NCDs showed declining trends during the Ebola period, PUD showed a moderately increasing trend.

\section{Changes in sex distribution}

The female to male ratios for each NCD in the pre-Ebola and the Ebola outbreak periods are shown in Table 1. For every disease there was an increase in the proportion of females in the Ebola period compared with the pre-Ebola period, although this was significant only for HTN, DM and cancer/tumour.

\section{Pattern of NCDs between different types of health-care facility}

The burden and patterns of the six NCDs in the three types of health facility (PHU, secondary and tertiary hospitals) in the pre-Ebola and the Ebola periods are shown in Table 2. There was a marked decline in all NCDs combined from the pre-Ebola to the
Ebola periods; this was most pronounced in the tertiary (70\% decline) and secondary (91\% decline) hospitals compared with the PHUs (25\% decline). In the secondary and tertiary hospitals there was a decline in each of the six NCDs that was highly significant in both types of hospitals for the high-burden diseases, HTN and DM. The PHUs had similar findings, with the exception that more patients presented with PUD in the Ebola outbreak period compared with the pre-Ebola period.

\section{DISCUSSION}

This is the first study from Sierra Leone to assess the effect of the Ebola disease outbreak on NCDs, and it is important in view of the rapidly growing burden of NCDs and their effect on premature mortality around the world, including Africa. ${ }^{14}$ There were some important findings. First, while monthly report submissions were excellent, the completeness of reporting on NCDs was suboptimal, with a further decline in this parameter in the Ebola period. Second, there was a declining trend in all the NCDs combined during the study period, which was more marked during the Ebola outbreak. This decline was mirrored in each of the NCDs, with the exception of PUD. Third, the overall decline in NCDs from the pre-Ebola period to the Ebola period, especially for major diseases such as HTN and DM, was more marked in the tertiary and district hospitals compared with the PHUs. Again, the exception was PUD, which increased in the Ebola period. Finally, there was an increase in the proportion of females presenting with NCDs in the Ebola period; the difference was significant for HTN, DM and cancer/tumour.

This study had several strengths. It was district-based and there was $100 \%$ submission of the monthly reports from all levels of the health system, from PHU to tertiary level care. While some data on NCDs were incomplete, reported information was double-entered and verified for errors in EpiData to assure quality of the data for analysis. The conduct and reporting of this study also followed the STrengthening the Reporting of OBservational studies in Epidemiology (STROBE) guidelines, and adhered to sound ethics principles. ${ }^{15,16}$ There were some weaknesses, nevertheless. The study was conducted using routine aggregate reports, and data accuracy could not be verified. As reports were 
A
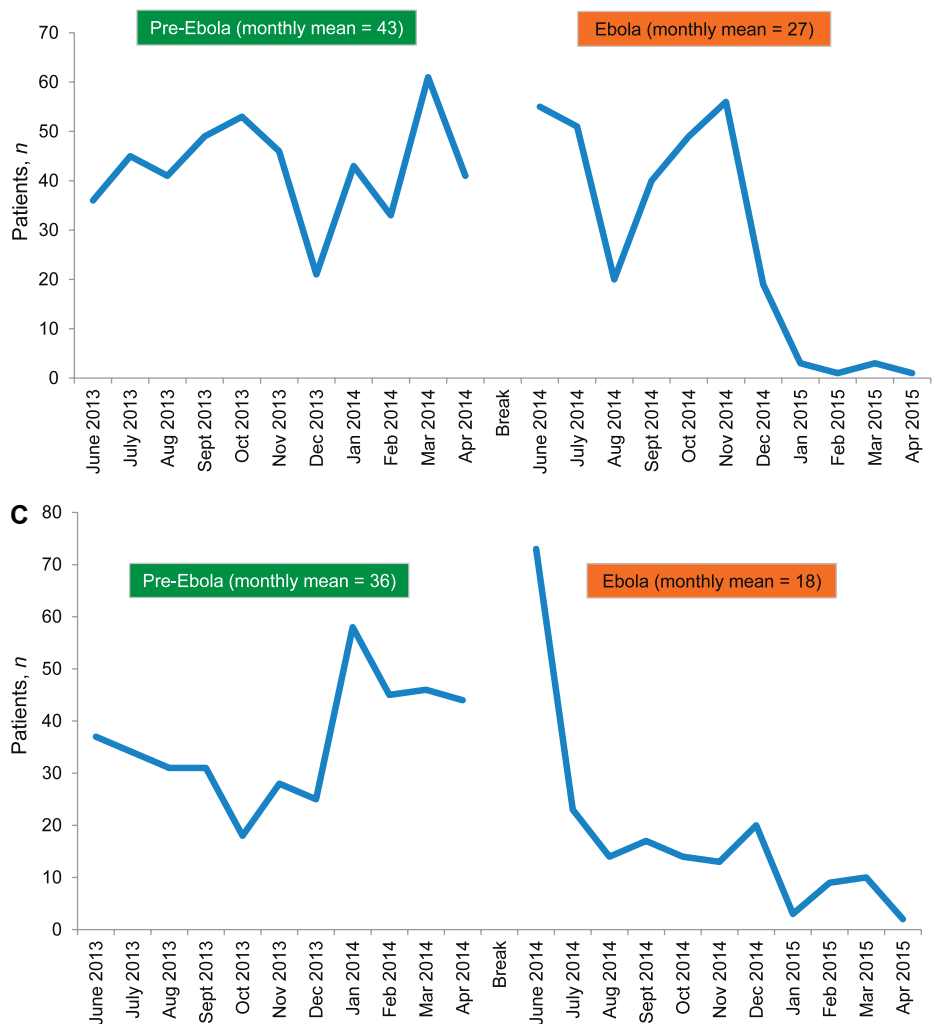

E

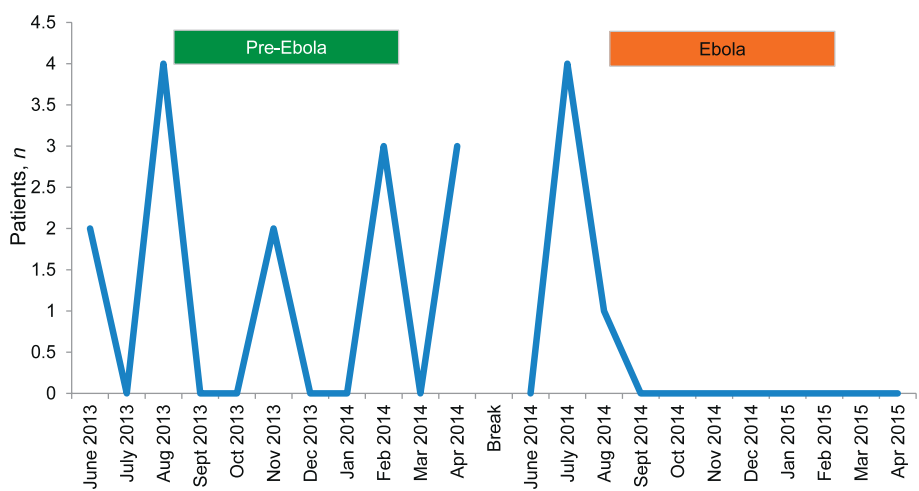

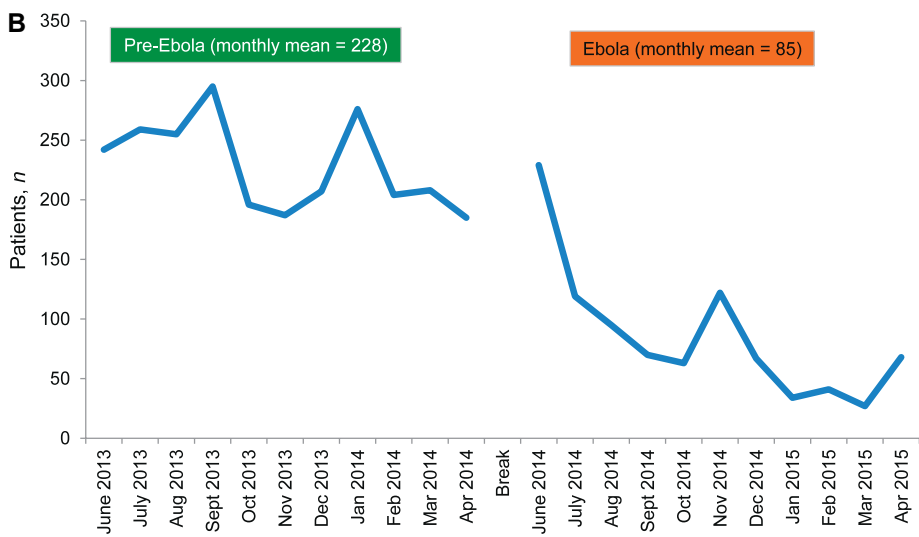
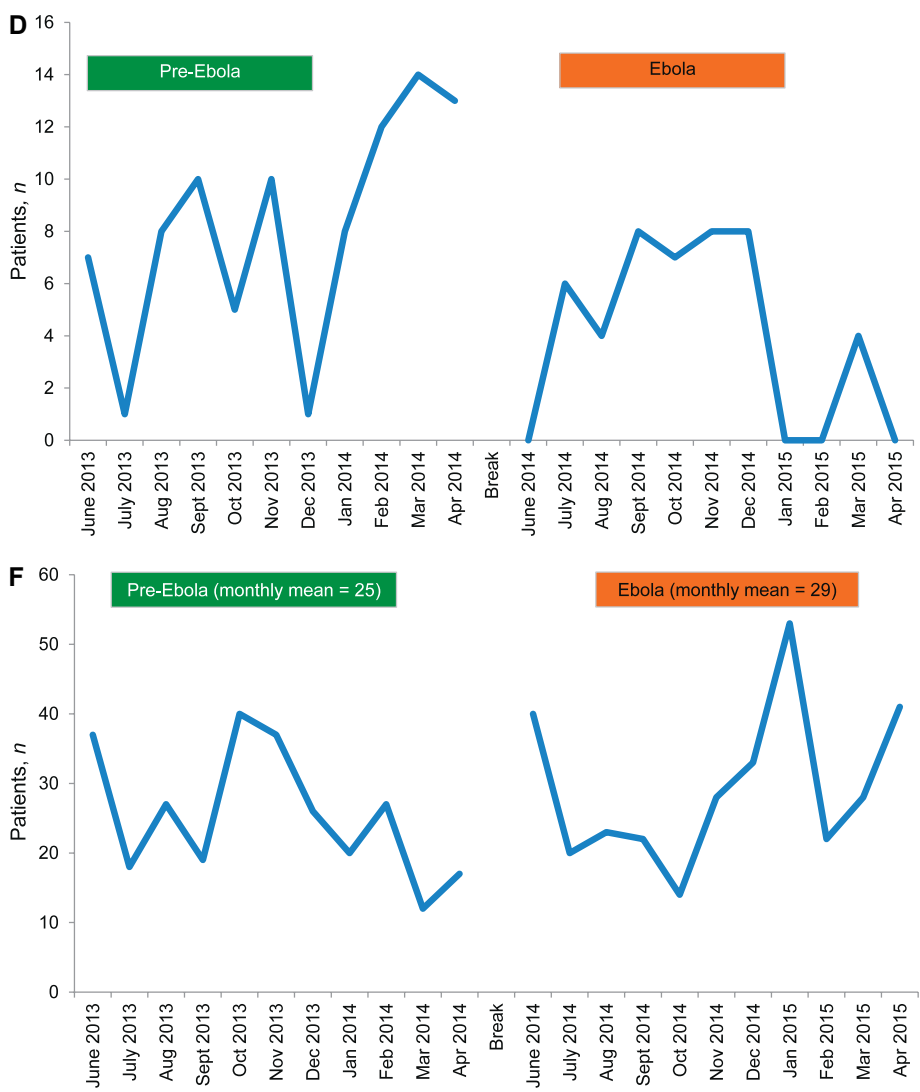

FIGURE 2 A) Cardiovascular disease. B) Hypertension. C) Diabetes mellitus. D) Cancer/tumour. E) Mental health disease. F) Peptic ulcer disease. Numbers of patients reported each month with a different NCD at health facilities in the pre-Ebola and the Ebola periods, Western District, Sierra Leone, 2013-2015. Pre-Ebola period = 1 June 2013-30 April 2014; Ebola period = 1 June 2014-30 April 2015. NCD = non-communicable diseases.

available only from the public health facilities, we could not report on the NCD trends in private health care settings. The representative health facilities, especially the PHUs, were selected based on convenience sampling, and there may thus be some inherent bias that could have led to an overestimation or underestimation of the extent of the decrease in the reported NCDs. Many patients with MHD may also have attended the mental health hospital, which was not included in the representative sample for the study.

The downward trends observed for most NCDs during the Ebola disease outbreak are likely to be due to a decrease in clinic attendance, as well as the closure and repurposing of some health facilities for the Ebola response. ${ }^{11}$ It is also likely that redeploy- ment of skilled human resources and the tragic deaths of healthcare workers due to Ebola worsened the situation. With little care available in the public health sector, patients might have resorted to seeking treatment from the private sector or may have selftreated by purchasing over-the-counter medicines during the Ebola outbreak; this may have been easier to do for CVD, HTN and DM, although we have no information about these practices nor evidence for these hypotheses.

CVD, HTN and DM were the most common NCDs observed at all levels of health care, including the PHUs, in line with other published studies from Africa examining NCD management at peripheral health centres. ${ }^{7,8}$ As PUD requires endoscopy for a definitive diagnosis, which is not possible at most health-care levels 
TABLE 1 Female to male ratio in selected NCDs reported in selected health facilities in the pre-Ebola and Ebola outbreak periods, Western District, Sierra Leone, 2013-2015*

\begin{tabular}{|c|c|c|c|c|}
\hline Disease & $\begin{array}{c}\text { Pre-Ebola }{ }^{\dagger} \\
\text { period } \\
n(\%)\end{array}$ & $\begin{array}{c}\text { Ebola } ¥ \text { period } \\
n(\%)\end{array}$ & $\begin{array}{c}\text { OR } \\
(95 \% \mathrm{Cl})\end{array}$ & $P$ value \\
\hline \multicolumn{5}{|l|}{ CVD } \\
\hline Male & $244(54)$ & $118(49)$ & & \\
\hline Female & $209(46)$ & $125(51)$ & $1.2(0.9-1.7)$ & 0.2 \\
\hline \multicolumn{5}{|l|}{ HTN } \\
\hline Male & $952(42)$ & $213(30)$ & & \\
\hline Female & $1320(58)$ & $493(70)$ & $1.7(1.4-2.0)$ & $<0.001$ \\
\hline \multicolumn{5}{|l|}{ DM } \\
\hline Male & 177 (49) & $44(35)$ & & \\
\hline Female & $183(51)$ & $81(65)$ & $1.8(1.2-2.7)$ & $<0.01$ \\
\hline \multicolumn{5}{|c|}{ Cancer/tumour } \\
\hline Male & $46(56)$ & $6(13)$ & & \\
\hline Female & $36(44)$ & $39(87)$ & $8.3(3.2-21.8)$ & $<0.001$ \\
\hline \multicolumn{5}{|l|}{ MHD } \\
\hline Male & $8(67)$ & $1(20)$ & & \\
\hline Female & $4(33)$ & $4(80)$ & $8.0(0.7-97.3)$ & 0.1 \\
\hline \multicolumn{5}{|l|}{ PUD } \\
\hline Male & $102(42)$ & $116(41)$ & & \\
\hline Female & $141(58)$ & $168(59)$ & $1.0(0.7-1.5)$ & 0.8 \\
\hline
\end{tabular}

* Source: District Health Information System, Directorate of Health Systems, Policy, Planning and Information, Ministry of Health and Sanitation, Freetown, Sierra Leone.

$\dagger$ Pre-Ebola period = June 2013-April 2014

¥Ebola period = June 2014-April 2015.

$\mathrm{NCD}=$ non-communicable disease $\mathrm{OR}=$ odds ratio; $\mathrm{Cl}=$ confidence interval CVD = cardiovascular disease; HTN = hypertension; $\mathrm{DM}=$ diabetes mellitus; $\mathrm{MHD}=$ menta health disease; PUD = peptic ulcer disease.

in Africa, the reports on PUD essentially include patients presenting with upper abdominal pain who are clinically diagnosed with PUD. The increase in reports of PUD during the Ebola period is intriguing and requires further research. Possible explanations may be that patients were more likely to present to hospital with abdominal pain, as this is a recognised symptom of EVD,17 the excessive use of high-dose antipyretics and analgesics to deal with fever, ${ }^{18}$ or Ebola outbreak-induced stress. ${ }^{19}$ We do not know why a higher proportion of females presented with NCDs during the Ebola outbreak compared with pre-Ebola, but this may be related to the general observation that women are more likely to access health services in general in Africa compared with men. ${ }^{20}$

This study has important implications. First, measures need to be taken to strengthen regular and comprehensive reporting of NCDs at all levels of the health care system. This requires simple but suitable monitoring systems combined with staff training and supervision. Consideration should also be given to electronic medical records, which have been successfully deployed and used for chronic NCDs at peripheral heath centres in Africa and elsewhere.8,21,22 The private sector needs to be included in plans and implementation.

Second, as the decline in NCDs was less marked in the PHUs compared with the secondary or tertiary hospitals between the pre-Ebola and Ebola periods, the diagnosis and management of NCDs at peripheral level needs to be strengthened. This is already being done in other African countries, 7,8 and the lessons learnt need to be shared and taken up. Finally, more research is needed as to why there were sex differences and increases in reports of PUD between the pre-Ebola and Ebola periods.

In conclusion, this study shows that comprehensive reporting of NCDs was sub-optimal and decreased during the Ebola epi-
TABLE 2 Burden and patterns of NCDs by type of health facility in the pre-Ebola and Ebola outbreak periods, Western District, Sierra Leone, 2013-2015*

\begin{tabular}{|c|c|c|c|}
\hline $\begin{array}{l}\text { Type of health } \\
\text { facility and } \\
\text { selected diseases }\end{array}$ & $\begin{array}{c}\text { Pre-Ebola }{ }^{\dagger} \\
n(\%)\end{array}$ & $\begin{array}{l}\text { Ebola } \\
n(\%)\end{array}$ & $P$ value $\S$ \\
\hline $\begin{array}{l}\text { Peripheral health } \\
\text { unit }\end{array}$ & 1135 & 853 & \\
\hline CVD & $42(4)$ & $14(2)$ & 0.003 \\
\hline HTN & 871 (77) & $497(58)$ & $<0.001$ \\
\hline $\mathrm{DM}$ & $15(1)$ & $54(6)$ & $<0.001$ \\
\hline Cancer/tumour & $1(0)$ & $8(1)$ & 0.002 \\
\hline MHD & $11(1)$ & $5(2)$ & 0.2 \\
\hline PUD & $195(17)$ & $275(32)$ & $<0.001$ \\
\hline $\begin{array}{l}\text { Secondary } \\
\text { hospitals }\end{array}$ & 604 & 53 & \\
\hline CVD & $58(10)$ & $4(8)$ & 0.3 \\
\hline HTN & $446(74)$ & $32(60)$ & 0.02 \\
\hline $\mathrm{DM}$ & $49(8)$ & $8(15)$ & 0.04 \\
\hline Cancer/tumour & $3(0)$ & 0 & 0.4 \\
\hline MHD & 0 & 0 & 0.2 \\
\hline PUD & $48(8)$ & $9(17)$ & 0.01 \\
\hline $\begin{array}{l}\text { Tertiary } \\
\text { hospital }\end{array}$ & 1663 & 502 & \\
\hline CVD & $333(20)$ & $225(45)$ & $<0.001$ \\
\hline HTN & $955(57)$ & $177(35)$ & $<0.001$ \\
\hline DM & $296(18)$ & $63(13)$ & 0.002 \\
\hline Cancer/tumour & $78(5)$ & $37(7)$ & 0.009 \\
\hline MHD & $1(0)$ & 0 & 0.4 \\
\hline PUD & 0 & 0 & 0.4 \\
\hline
\end{tabular}

* Source: District Health Information System, Directorate of Health Systems, Policy, Planning and Information, Ministry of Health and Sanitation, Freetown, Sierra Leone. $\dagger$ Pre-Ebola period = June 2013-April 2014.

$\ddagger$ Ebola period = June 2014-April 2015.

$\S$ Mantel-Haenszel $\chi^{2}$.

$\mathrm{NCD}=$ non-communicable disease $; \mathrm{CVD}=$ cardiovascular disease; $\mathrm{HTN}=$ hypertension; $\mathrm{DM}=$ diabetes mellitus; $\mathrm{MHD}=$ mental health disease; $\mathrm{PUD}=$ peptic ulcer disease.

demic. There was a general decline in all reported NCDs between the pre-Ebola and the Ebola periods, which was more marked in the hospitals than in the PHUs. Interesting observations were that a higher proportion of females presented with NCDs during the Ebola outbreak and that there was an increase in reports of PUD.

\section{References}

1 Mathers C D, Loncar D. Projections of global mortality and burden of disease from 2002 to 2030. PLOS Med 2006; 3: e442.

2 Lozano R, Naghavi M, Foreman K, et al. Global and regional mortality from 235 causes of death for 20 age groups in 1990 and 2010: a systematic analysis for the Global Burden of Disease Study 2010. Lancet 2012; 380: 2095 2128

3 World Health Organization. Global status report on noncommunicable diseases 2014. Geneva, Switzerland: WHO, 2014.

4 World Health Organization. A comprehensive global monitoring framework, including indicators, and a set of voluntary global targets for the prevention and control of noncommunicable diseases. Revised WHO discussion paper: 25 July 2012. Geneva, Switzerland: WHO, 2012.

5 Beaglehole R, Bonita R, Horton R, et al. Measuring progress on NCDs: one goal and five targets. Lancet 2012; 380: 1283-1285.

6 United Nations. Transforming our world: the 2030 agenda for sustainable development. New York, NY, USA: UN, 2016. http://sustainabledevelopment.un.org/post2015/transformingourworld Accessed March 2017.

7 Sobry A, Kizito W, Van den Bergh R, et al. Caseload, management and treatment outcomes of patients with HTN and/or DM in a primary health care programme, in an informal setting, Kibera, Nairobi, Kenya. Trop Med Int Health 2013; 19: 47-57. 
8 Manjomo R C, Mwagomba B, Ade S, et al. Managing and monitoring chronic non-communicable diseases in a primary health care clinic, Lilongwe, Malawi. Public Health Action 2016; 6: 60-65.

9 Baize S, Pannetier D, Oestereich L, et al. Emergence of Zaire Ebola virus disease in Guinea. N Engl J Med 2014; 15: 1418-1425.

10 World Health Organization. Ebola situation reports. Geneva, Switzerland: WHO, 2017. http://apps.who.int/ebola/current-situation/ebola-situation-report-6-january-2016 Accessed March 2017

11 Edelstein M, Angelides P, Heyman D L. Ebola: the challenging road to recovery. Lancet 2015; 385: 2234-2235.

12 Statistics Sierra Leone. Sierra Leone 2015 population and housing census. Provisional results. March 2016. Freetown, Sierra Leone: Statistics Sierra Leone, 2016.

13 World Health Organization. World Health Statistics, 2014. Geneva, Switzerland: WHO, 2014.

14 Norheim O F, Jha P, Admasu K, et al. Avoiding 40\% of the premature deaths in each country, 2010-30: review of national mortality trends to help quantify the UN sustainable development goal for health. Lancet $2015 ; 385$ : 239-252.

15 von Elm E, Altman D G, Egger M, et al. The STrengthening the Reporting of OBservational studies in Epidemiology (STROBE) statement: guidelines for reporting observational studies. Lancet 2007; 370: 1453-1457.
16 Edginton M, Enarson D, Zachariah R, et al. Why ethics is indispensable for good-quality operational research. Public Health Action 2012; 2: 21-22.

17 Beeching N J, Fenech M, Houlihan C F. Ebola virus disease. BMJ 2014; 349: 26-30.

18 Schoen R T, Vender R J. Mechanisms of nonsteroidal anti-inflammatory drug-induced gastric damage. Am J Med 1989; 86: 449-458.

19 Levenstein S, Rosenstock S, Jacobsen R K, Jorgensen T. Psychological stress increases risk for peptic ulcer, regardless of Helicobacter pylori infection or use of nonsteroidal anti-inflammatory drugs. Clin Gastroenterol Hepatol 2015; 13: 498-506.

20 Bertakis K D, Azari R, Helms L J, Callahan E J, Robbins J A. Gender differences in the utilization of health care services. J Fam Pract 2000; 49: 147 152.

21 Khader A, Farajallah L, Shahin Y, et al. Cohort monitoring of persons with diabetes mellitus in a primary health care clinic for Palestine refugees in Jordan. Trop Med Int Health 2012; 17: 1108-1116.

22 Khader A, Farajallah L, Shahin Y, et al. Cohort monitoring of persons with hypertension: an illustrated example from a primary healthcare clinic for Palestine refugees in Jordan. Trop Med Int Health 2012; 17 1163-1170.
Contexte: Vingt-sept unités de soins de santé primaires, cinq hôpitaux secondaires et un hôpital tertiaire, District de la Zone Ouest, Sierra Leone.

Objectifs: Décrire les systèmes de reportage, la fréquentation mensuelle et les profils dans les structures de santé de six maladies non transmissibles (MNT) dans les périodes avant Ebola et après Ebola.

Schéma : Etude transversale basée sur les données du programme.

Résultats: Pour les six MNT sélectionnées, les rapports ont été complets à $89 \%$ avant Ebola et à $86 \%$ pendant la période Ebola $(P<$ $0,01)$. Dans l'ensemble, il y a eu des tendances marquées au déclin des MNT signalées dans la période Ebola, avec un nombre mensuel moyen de 342 avant Ebola et 164 pendant Ebola. Le nombre mensuel moyen de MNT signalées pendant les périodes avant Ebola et pendant Ebola a été le suivant : hypertension 228 contre 85 ; maladies cardiovasculaires 43 contre 27 ; diabète 36 contre 18 ; et ulcère gastrique, qui a augmenté de 25 à 29. Des proportions plus élevées de femmes ont eu des MNT pendant Ebola comparé à la période avant Ebola. Le nombre de patients avec MNT (sauf l'ulcère gastrique) a décliné de $25 \%$ dans les unités de soins de santé primaires, de $91 \%$ dans les hôpitaux secondaires et de $70 \%$ dans des hôpitaux tertiaires entre les périodes avant Ebola et pendant Ebola.

Conclusion : Le reportage complet des MNT a été sous-optimal et a diminué pendant l'épidémie d'Ebola. II y a eu dans les hôpitaux des déclins marqués dans la fréquentation rapportée en matière de MNT entre les périodes avant Ebola et pendant Ebola. II y a des implications majeures de cette étude en termes de politique, qui incluent le renforcement du diagnostic et de la prise en charge des MNT dans des unités de santé périphériques et des rapports réguliers et complets des MNT à tous les niveaux du système de soins de santé.
Marco de referencia: Veintisiete unidades primarias de atención de salud, cinco hospitales de atención secundaria y un hospital de atención terciaria en el Distrito de la Región Occidental de Sierra Leona.

Objetivos: Describir los sistemas de notificación, las consultas mensuales y la distribución de seis enfermedades no transmisibles (NCD) en los establecimientos sanitarios durante el período del brote epidémico de enfermedad del Ébola y antes del mismo.

Método: Fue este un estudio transversal a partir de los datos programáticos.

Resultados: La notificación con respecto a las seis NCD escogidas fue completa en un $89 \%$ antes del brote epidémico y en $86 \%$ durante el período del brote por el virus del Ébola $(P<0,01)$. En general, se observó una notable tendencia decreciente de las NCD durante el período del brote, con cifras mensuales promedio de 342 antes del brote y 164 durante el mismo. Las cifras mensuales promedio del período anterior al brote del Ébola y durante el mismo fueron las siguientes: hipertensión arterial 228 contra 85; enfermedades cardiovasculares 43 contra 27; diabetes 36 contra 18; y la úlcera péptica aumentó de 25 a 29. Una mayor proporción de mujeres presentó NCD durante el brote por el virus del Ébola, en comparación con el período anterior. El número de casos de NCD (con la excepción de la enfermedad ulcerosa péptica) disminuyó un $25 \%$ en las unidades de atención primaria, un $91 \%$ en los establecimientos de atención secundaria y un $70 \%$ en los hospitales terciarios entre el período anterior al brote epidémico de Ébola y durante el mismo.

Conclusión: La exhaustividad de la notificación de las NCD era deficiente y disminuyó durante la epidemia de la enfermedad del Ébola. Se observó también una disminución de las consultas notificadas por NCD entre el período anterior al brote y durante el mismo y la disminución fue más notable en los hospitales. De los resultados del presente estudio se deducen importantes implicaciones en materia de políticas, como la necesidad de fortalecer el diagnóstico y el tratamiento de las NCD en las unidades periféricas de atención de salud y de fomentar la notificación periódica y exhaustiva de NCD en todos los niveles del sistema de atención de salud.
Public Health Action (PHA) The voice for operational research Published by The Union (www.theunion.org), PHA provides a platform to fulfil its mission, 'Health solutions for the poor'. PHA publishes high-quality scientific research that provides new knowledge to improve the accessibility, equity, quality and efficiency of health systems and services.
e-ISSN 2220-8372

Editor-in-Chief: Dermot Maher, MD, Switzerland

Contact: pha@theunion.org

PHA website: http://www.theunion.org/what-we-do/journals/pha

Article submission: http://mc.manuscriptcentral.com/pha 